\title{
Assessment of the Berlin Questionnaire for evaluation of hypoxemia risk in subjects undergoing deep sedation for screening gastrointestinal endoscopy
}

This article was published in the following Dove Press journal:

Therapeutics and Clinical Risk Management

\author{
Shiue-Chin Liou' \\ Chen-Ming $\mathrm{Hsu}^{2}$ \\ Chit Chen' \\ Ming-Yao Su ${ }^{2}$ \\ Cheng-Tang Chiu²
}

'Department of Anesthesiology, Chang Gung Memorial Hospital at Taoyuan,

Taoyuan, Taiwan; ${ }^{2}$ Department of Gastroenterology and Hepatology, Chang Gung Memorial Hospital at Linkou, Chang Gung University College of Medicine, Taoyuan, Taiwan
Correspondence: Chen-Ming Hsu Department of Gastroenterology and Hepatology, Chang Gung Memorial Hospital at Linkou, Chang Gung University College of Medicine, 5 Fusing Street, Kweishan Township, Taoyuan County 333, Taiwan

Tel +8863328 I200 ext 8I0I

Email hsu3060e@adm.cgmh.org.tw
Background: Subjects with obstructive sleep apnea (OSA) are vulnerable to sedation-related complications during endoscopic procedures. A significant portion of subjects undergoing routine endoscopy is at high risk of OSA, but most are undiagnosed. The purpose of this study was to estimate the prevalence of high risk for OSA among Chinese subjects undergoing deep sedation for screening gastrointestinal endoscopy and to evaluate the hypoxemia risk of these examinees stratified by Berlin Questionnaire (BQ).

Patients and methods: We performed a prospective cohort study in subjects undergoing deep sedation with monitored anesthesia care for combined esophagogastroduodenoscopy plus colonoscopy. Subjects who were Chinese were stratified into high- and low-risk groups for OSA by administration of BQ. Deep sedation was achieved via a propofol target-controlled infusion system. Hypoxemia was defined as pulse oximetry reading of less than $90 \%$. The frequency of hypoxemia was compared between high- and low-risk groups for OSA.

Results: A total of 615 Chinese subjects were recruited during the study period, and 614 subjects were included for analysis. Two hundred eighteen (35.5\%) subjected were classified to be at high risk of OSA, and $396(64.5 \%)$ were stratified to be at low risk of OSA by BQ. Hypoxemia occurred in $83(13.5 \%)$ subjects during endoscopy procedures. The risk of developing hypoxemia in the high-risk group was significantly higher when compared to that of the low-risk group subjects (24.8\% vs 7.3\%; relative risk, 3.37; 95\% CI, 2.22-5.13).

Conclusion: About one-third Chinese subjects undergoing deep sedation for screening endoscopy were at high risk of OSA. Subjects at high risk of OSA are associated with an increased risk of hypoxemia in comparison to the low-risk group when undergoing deep sedation for screening gastrointestinal endoscopy.

Keywords: endoscopy, deep sedation, hypoxemia, obstructive sleep apnea, monitored anesthesia care, Berlin Questionnaire

\section{Introduction}

Esophagogastroduodenoscopy (EGD) and colonoscopy are widely used to investigate the disorders of upper gastrointestinal (GI) and colonic tracts. However, people are fear of endoscopic examination due to the discomfort related to these procedures. For relief of discomfort, the use of sedation is considered by many endoscopists to be an integral part of endoscopic examinations. ${ }^{1}$ The degree of sedation can be divided into four levels: minimal sedation, moderate sedation, deep sedation, and general anesthesia. ${ }^{1-3}$ Even though the desired level of sedation could be achieved by proper use of sedative 
agents, these drugs may result in depression of cardiac or respiratory function. ${ }^{1,4}$ Depth of sedation is directly related to the ability of maintenance of cardiopulmonary function. In general, deeper level of sedation may be associated with higher risk of cardiopulmonary complications. ${ }^{4}$ Indeed, about $50 \%$ of the morbidity and mortality associated with GI endoscopy are cardiopulmonary adverse events (AEs), which may be related to the use of sedation. ${ }^{5}$

Most cardiopulmonary AEs are related to the underlying diseases of the patients. ${ }^{6}$ Patients with obstructive sleep apnea (OSA) are prone to upper airway obstruction during sedation due to the depression of pharyngeal muscle tone and arousal response by sedative agents. ${ }^{3}$ Previous studies reveal that a significant portion of patients undergoing routine endoscopy are at high risk of OSA. ${ }^{7,8}$ However, most patients with OSA are undiagnosed when undergoing endoscopic examination..$^{9-12}$ Although the standard diagnostic method of OSA is polysomography, ${ }^{13}$ such a test is expensive, time consuming, and not suitable for pre-sedation evaluation. ${ }^{8}$ Alternatively, Berlin Questionnaire (BQ) is easy to use to identify patients with a high risk for OSA. ${ }^{14,15}$

The aim of this study was to estimate the prevalence of Chinese subjects undergoing deep sedation for screening GI endoscopy who are at risk of OSA and to evaluate the hypoxemia risk of these subjects stratified by BQ.

\section{Patients and methods}

With approval of Chang Gung Medical Foundation Institutional Review Board (N100-2215B), we performed a prospective cohort study in subjects undergoing deep sedation with monitored anesthesia care for same-day EGD and colonoscopy as part of a voluntary health checkup at Chung-Gung Memorial Hospital Taoyuan branch. Chinese subjects were considered eligible to participate if they were 18 years of age and older and scheduled for combined EGD and colonoscopy. Exclusion criteria were as follows: 1) 18 years and younger, 2) allergy to propofol, eggs or soybeans, 3) pregnancy, 4) significant cardiopulmonary diseases such as congestive heart failure, arrhythmia, asthma attack or chronic obstructive pulmonary disease, 5) American Society for Anesthesiology (ASA) class III-V, and 6) refusal or inability to complete the questionnaire. Only subjects who met the eligibility criteria on the days that the principal investigators (S-CL and/or C-MH) were available were recruited, and all participants provided written informed consent. The study was conducted according to the principles expressed in the Declaration of Helsinki.

\section{Pre-procedure assessment}

The BQ was administered to the participants by the anesthesiologist (S-CL) before endoscopic examinations. The BQ consisted of three categories. ${ }^{14-16}$ First, the subject was asked questions about snoring and witnessed apneas (category 1 ). The subject received a positive score if he or she reported snoring and/or witnessed apneas more than three to four times per week or almost every day. Second, the subject was asked questions about excessive daytime sleepiness (category 2). The subject received a positive score if he or she reported feeling drowsy upon awakening, daytime sleepiness and/or drowsy driving more than three to four times per week or almost every day. Third, if the subject had a history of hypertension or obesity, the subject received a positive score (category 3 ). Hypertension was defined as systolic blood pressure $\geq 140 \mathrm{mmHg}$, diastolic blood pressure $\geq 90 \mathrm{mmHg}$ or taking medications for hypertension. Obesity was defined as body mass index (BMI) $\geq 25 \mathrm{~kg} / \mathrm{m}^{2}$ according to the proposal of World Health Organization Western Pacific Regional Office for the cutoff point of BMI for obesity in Asian population. ${ }^{17}$ BMI was defined as weight ( $\mathrm{kg}$ ) divided by height ( $\mathrm{m}$ ) squared, ie, $\mathrm{kg} / \mathrm{m}^{2}$. The participants had to complete the questionnaires before endoscopy. Demographic data, which included age, sex, body height and weight, initial blood pressure, and heart rate, were collected by a certified registered nurse anesthetist. Pre-sedative evaluation included a medical history and focused physical examination performed by an anesthesiologist (S-CL). The oropharyngeal area was checked and a Mallampati score was recorded.

\section{Sedation and patient monitoring}

The subjects underwent EGD followed by colonoscopy in the study. All participants received routine monitoring, which included continuous electrocardiography (lead II), blood pressure (automated non-invasive blood pressure cuff, serial measurements), heart rate, respiration rate, pulse oximetry, and end-tidal $\mathrm{CO}_{2}$ (capnography). All participants were given oxygen at $6 \mathrm{~L} / \mathrm{min}$ via nasal cannula at the onset of sedation and throughout the whole procedure. Deep sedation was achieved by using a propofol target-controlled infusion (TCI) system (Diprivan; AstraZeneca UK, Macclesfield, UK) with Marsh model following a bolus of fentanyl $(50 \mu \mathrm{g})$ and $2 \%$ lidocaine (40 mg). Based on the patients' sex, age, body weight, and height, the TCI infusion system can calculate the starting dose of propofol and the subsequent infusion rate required to maintain the desired target effect site concentration (Ce). The Ce was initially set at $2.0 \mu \mathrm{g} / \mathrm{mL}$ and was adjusted to keep subjects in deep sedation level throughout the whole procedure. The level of sedation was evaluated by 
the anesthesiologist (S-CL) using modified observer's assessment of alertness/sedation scale (MOAA/S) (Table 1). ${ }^{1,4}$ Level of deep sedation was defined as a MOAA/S score $\leq 1$. Hypoxemia was defined as a pulse oximetry reading of $<90 \%$ for any duration with assurance of proper placement of probes. Hypopnea/apnea was defined as respiration rate less than 6 breaths/min based on capnography. A certified registered nurse anesthetist recorded the data on hypoxemia, hypopnea, and apnea events at the bedside. Airway maneuvers (AMs) were defined as the use of any method to assist the ventilation, such as chin lift maneuver, nasopharyngeal airway insertion, mask ventilation, or endotracheal intubation. AMs were performed for hypoxemia, hypopnea, upper airway obstruction, or any kind of abnormal respiration pattern at the discretion of the anesthesiologist.

\section{Statistical analysis}

The minimal sample size of this study was determined to be 584 evaluable subjects. It was based on an $80 \%$ power and a two-sided $\alpha$ of 0.05 with the assumption that the prevalence of OSA was $32 \%$ in the study population and the hypoxemia rates were $12 \%$ and $5 \%$ for subjects at high risk of OSA and not at high risk of OSA, respectively. ${ }^{7,8,14}$

Subjects were stratified into high-risk and low-risk groups for OSA based on their responses to the BQ. The subject was classified as high risk for OSA if he or she had positive scores in at least two of the three categories. ${ }^{14,15}$ Quantitative data were reported as mean and SD, whereas categorical data were described as proportions. The rates of hypoxemia and use of AMs between high-risk group and low-risk group for OSA were compared by using chi-square test. Relative risk and a 95\% CI for developing hypoxemia and intervention in the high-risk OSA group were calculated. Demographic, procedural, and sedative data were compared between groups by using a chi-square test for categorical variables and an unpaired $t$-test or the Mann-Whitney test for quantitative variables. $P$-values less than 0.05 were considered significant.

Table I Modified observer's assessment of alertness/sedation scale

\begin{tabular}{ll}
\hline Response to external stimulus & Score \\
\hline Agitated & 6 \\
Responds readily to name spoken in normal tone & 5 \\
Lethargic response to name spoken in normal tone & 4 \\
Responds only after name is called loudly and/or repeatedly & 3 \\
Responds only after mild prodding or shaking & 2 \\
Does not respond to mild prodding or shaking & 1 \\
Does not respond to painful stimulus & 0 \\
\hline
\end{tabular}

All statistical analyses were performed using SPSS Statistics version 17.0 (SPSS Inc., Chicago, IL, USA).

\section{Results}

A total of 615 subjects who met the inclusion and exclusion criteria and completed the BQ were recruited during the study period. All subjects except one underwent same-day EGD and colonoscopy. Therefore, 614 subjects were included for analysis. The mean age of the subjects was $49.9 \pm 11.5$ years (range 20-78 years). Male subjects accounted for $56.5 \%$ (347/614). Of these subjects, 137 (22.3\%) had a history of hypertension and $227(37 \%)$ had BMI greater than $25 \mathrm{~kg} / \mathrm{m}^{2}$.

The mean endoscopy time was $18.8 \pm 4.6$ min (range 9.3-38 $\mathrm{min})$. The mean induction propofol dose was $7.8 \pm 2.1 \mathrm{mg}$ (range 4.2-19.0 mg), and the mean total propofol was $171 \pm 41 \mathrm{mg}$ (range $91-372 \mathrm{mg}$ ). The mean Ce of propofol was $3.0 \pm 0.23 \mu \mathrm{g} / \mathrm{mL}$ at the start of EGD, $3.1 \pm 0.48 \mu \mathrm{g} / \mathrm{mL}$ at the end of EGD, and $2.6 \pm 0.35 \mu \mathrm{g} / \mathrm{mL}$ during colonoscopy. The mean Ce of propofol during colonoscopy was less than that during EGD $(P<0.001)$. Hypoxemia occurred in $83(13.5 \%)$ subjects during endoscopy procedures, including $56(9.1 \%)$ subjects during EGD and 38 (6.2\%) subjects during colonoscopy. Chin lift maneuvers were used in 99 (16.1\%) subjects, including 70 (11.4\%) subjects during EGD and 47 (7.7\%) subjects during colonoscopy. Four (0.7\%) subjects received transient mask ventilation during colonoscopy due to hypopnea and/or hypoxemia. There was neither apnea nor endotracheal intubation in the study.

According to the stratification of the BQ, 218 (35.5\%) subjects were considered to be at high risk of OSA, and $396(64.5 \%)$ were considered to be at low risk of OSA. Demographic characteristics for these subjects are summarized in Table 2. Totally, 83 (13.5\%) subjects developed hypoxemia during endoscopy. A total of 54 (24.8\%) subjects in the high-risk group developed hypoxemia, and a total of 29 (7.3\%) subjects in the low-risk group developed hypoxemia (Table 3). The risk of developing hypoxemia in the high-risk group was significantly higher when compared with lowrisk group subjects (relative risk, 3.37; 95\% CI, 2.22-5.13). Sixty-one of 218 (28.0\%) high-risk subjects required AMs, while 37 of 396 (9.3\%) of low-risk subjects required AMs (relative risk, 2.99; 95\% CI, 2.06-4.35).

\section{Discussion}

Our data showed that about one-third of Chinese subjects undergoing screening GI endoscopic procedures were at high risk of OSA. The prevalence of OSA varies widely across 
Table 2 Demographic, procedural, and sedation data of low-risk and high-risk groups

\begin{tabular}{|c|c|c|c|}
\hline Variable & High risk $(n=2 \mid 8)$ & Low risk $(n=396)$ & $P$-value \\
\hline \multicolumn{4}{|l|}{ Demographic data } \\
\hline Mean age $\pm S D$, years & $51.5 \pm 10.8$ & $49.0 \pm 11.9$ & 0.011 \\
\hline Sex, male, n (\%) & $164(75.2)$ & $183(46.2)$ & $<0.001$ \\
\hline Mean height \pm SD $(\mathrm{cm})$ & $165.9 \pm 7.5$ & $162.5 \pm 8.8$ & $<0.001$ \\
\hline Mean weight \pm SD (kg) & $73.6 \pm 10.6$ & $60.0 \pm 10.0$ & $<0.001$ \\
\hline Mean BMI $\pm \mathrm{SD}\left(\mathrm{kg} / \mathrm{m}^{2}\right)$ & $26.7 \pm 2.8$ & $22.6 \pm 2.7$ & $<0.001$ \\
\hline HTN, n (\%) & $92(42.2)$ & $45(11.4)$ & $<0.001$ \\
\hline DM, n (\%) & $24(11.0)$ & $16(4.0)$ & 0.001 \\
\hline ASA class & & & $<0.001$ \\
\hline I, n (\%) & $103(47.2)$ & $315(79.5)$ & \\
\hline II, n (\%) & II $5(52.8)$ & $8 \mathrm{I}(20.5)$ & \\
\hline Mallampati score & & & $<0.001$ \\
\hline $\mathrm{I}, \mathrm{n}(\%)$ & $64(29.4)$ & $20 \mathrm{I}(50.8)$ & \\
\hline II, n (\%) & $119(54.6)$ & $185(46.7)$ & \\
\hline III, n (\%) & $35(16.0)$ & $10(2.5)$ & \\
\hline \multicolumn{4}{|l|}{ Procedure data } \\
\hline Mean EGD time $\pm S D$, min & $5.2 \pm 1.3$ & $5.3 \pm 1.5$ & 0.623 \\
\hline Mean colonoscopy time $\pm \mathrm{SD}$, min & $13.6 \pm 4.2$ & $13.6 \pm 4.3$ & 0.989 \\
\hline Total endoscopy time \pm SD, min & $18.4 \pm 4.3$ & $19.1 \pm 4.8$ & 0.065 \\
\hline \multicolumn{4}{|l|}{ Sedation data } \\
\hline Mean $\mathrm{TCl}$ propofol concentration at the initial of $\mathrm{EGD} \pm \mathrm{SD}, \mu \mathrm{g} / \mathrm{mL}$ & $3.0 \pm 0.2$ & $3.0 \pm 0.3$ & 0.176 \\
\hline Mean TCl propofol concentration at the end of EGD $\pm \mathrm{SD}, \mu \mathrm{g} / \mathrm{mL}$ & $3.0 \pm 0.5$ & $3.2 \pm 0.5$ & $<0.001$ \\
\hline Mean TCl propofol concentration during colonoscopy $\pm \mathrm{SD}, \mu \mathrm{g} / \mathrm{mL}$ & $2.5 \pm 0.3$ & $2.6 \pm 0.4$ & $<0.001$ \\
\hline Mean total propofol dose for EGD $\pm \mathrm{SD}, \mathrm{mg}$ & $116.9 \pm 24.3$ & $99.5 \pm 26.6$ & $<0.001$ \\
\hline Mean total propofol dose during colonoscopy $\pm \mathrm{SD}, \mathrm{mg}$ & $48.2 \pm 22.5$ & $51.6 \pm 30.0$ & 0.109 \\
\hline Mean total propofol dose \pm SD, mg & $181.6 \pm 35.4$ & $164.4 \pm 43.3$ & 0.009 \\
\hline End-tidal $\mathrm{CO}_{2}$ during colonoscopy $\pm \mathrm{SD}, \mathrm{mmHg}$ & $43.2 \pm 6.4$ & $4 I .1 \pm 6.4$ & $<0.001$ \\
\hline
\end{tabular}

Abbreviations: SD, standard deviation; BMI, body mass index; HTN, hypertension; DM, diabetes mellitus; ASA, American Society for Anesthesiology; EGD, esophagogastroduodenoscopy; $\mathrm{TCl}$, target-controlled infusion.

studies, with estimates ranging between $9 \%$ and $28 \%$ of the general adult population. ${ }^{12}$ Previous studies showed that the prevalence of high risk for OSA categorized by BQ was $26.3 \%-35.8 \%$ in primary care settings. ${ }^{16}$ In our study, the prevalence of high-risk subjects for OSA was $35.5 \%$, which was similar to other study. ${ }^{?}$

OSA is linked to difficult airway management and intubation; therefore, detection of the unrecognized OSA patients before sedation is important. ${ }^{12}$ However, it is not cost-effective to perform polysomnography in all patients undergoing sedation. Alternatively, some validated questionnaires may be useful tools for screening of OSA. ${ }^{18}$ The BQ has been used to screen OSA in primary care populations and surgical patients. ${ }^{14-16,19}$ The BQ may help in identifying high-risk patients with a sensitivity of $86 \%$ and specificity of $77 \%$ for predicting OSA with an respiratory disturbance index $>5 .{ }^{14}$ Another study revealed that the BQ had a sensitivity of $78.6 \%-87.2 \%$ for surgical patients with moderate to severe OSA. ${ }^{19}$

Table 3 Comparison of incidence of hypoxemia and use of AMs between high-risk and low-risk OSA groups

\begin{tabular}{llll}
\hline Hypoxemia/AMs & $\begin{array}{l}\text { High-risk group } \\
(\mathbf{n = 2 1 8 )}\end{array}$ & $\begin{array}{l}\text { Low-risk group } \\
(\mathbf{n = 3 9 6 )}\end{array}$ & $\begin{array}{l}\text { Relative risks } \\
\mathbf{( 9 5 \%} \mathbf{C l})\end{array}$ \\
\hline Hypoxemia & & & $2.8 \mathrm{I}(\mathrm{I.69-4.68)}$ \\
$\quad$ During EGD & $34(15.6 \%)$ & $22(5.6 \%)$ & $5.86(2.82-12.1)$ \\
$\quad$ During colonoscopy & $29(13.3 \%)$ & $9(2.3 \%)$ & $3.38(2.22-5.15)$ \\
$\quad$ During EGD and/or colonoscopy & $54(24.8 \%)$ & $29(7.3 \%)$ & \\
AMs & & & $2.42(1.55-3.78)$ \\
$\quad$ During EGD & $40(18.3 \%)$ & $30(7.6 \%)$ & $5.90(3.16-11.0)$ \\
$\quad$ During colonoscopy & $39(17.9 \%)$ & $12(3.0 \%)$ & $2.99(2.06-4.35)$ \\
$\quad$ During EGD and/or colonoscopy & $6 I(28.0 \%)$ & $37(9.3 \%)$ & \\
\hline
\end{tabular}

Abbreviations: AMs, airway maneuvers; EGD, esophagogastroduodenoscopy; OSA, obstructive sleep apnea. 
This study demonstrated that an increased frequency of hypoxemia developed in subjects identified by the BQ as being high risk for OSA when undergoing deep sedation for screening EGD and colonoscopy. Previous studies showed the BQ failed to accurately predict the risk of hypoxemia in patients undergoing moderate sedation for endoscopic procedures. ${ }^{7}$ However, our results were similar to Cote's study, which revealed an increased rate of hypoxemia and AMs in patients at risk of OSA screened by STOP-BANG questionnaire undergoing deep sedation for advanced endoscopic procedures when compared to low-risk group. ${ }^{8}$ This may be due to the varied vulnerability to airway obstruction in patients with OSA when the level of sedation is different. ${ }^{20}$ Under a moderate sedation level, the upper airway activity may be affected little but still functions well; therefore, patients with OSA can keep spontaneous breathing and maintain a narrowed but not be completely obstructed airway. However, under a deep sedation level, a condition resembling sleep, patients with OSA may be prone to obstruction of the upper airway, which often results in oxygen desaturation.

The risk of transient hypoxemia during oral route endoscopy is theoretically higher than during anal route due to potential upper airway compression, laryngeal irritation, or aspiration during insertion of upper GI endoscopy. In our study, more subjects developed hypoxemia during EGD than during colonoscopy. Another possible explanation of this phenomenon may be due to lower Ce of propofol during colonoscopy in our study.

There were some limitations of our study. First, the highrisk patients in our study did not undergo polysomnography examinations. Therefore, the exact percentage of OSA could not be defined. Only the frequency of patients at risk of OSA categorized by BQ could be defined. Second, we did not use evoked potential or bispectral index to monitor the sedation level. However, the MOAA/S scale, which is based on clinical assessment, is a good indicator of sedation depth in practice. ${ }^{1,4,8}$ Third, all the subjects in our study were ASA I-II patients, which comprised the most of ambulatory patients. Further study to evaluate the risk of hypoxemia in higher level of ASA patients when undergoing deep sedation for endoscopy is required.

\section{Conclusion}

Around one-third of Chinese subjects undergoing screening GI endoscopy were at high risk of OSA. Subjects at high risk of OSA undergoing deep sedation were associated with an increased risk of hypoxemia during endoscopic procedures when compared with the low-risk group. Screening of OSA by simple methods such as BQ is recommended in subjects who are scheduled to undergo deep sedation for endoscopic procedures.

\section{Author contributions}

All authors contributed toward data analysis, drafting and revising the paper and agree to be accountable for all aspects of the work.

\section{Disclosure}

The authors report no conflicts of interest in this work.

\section{References}

1. Cohen LB, Delegge MH, Aisenberg J, et al; AGA Institute. AGA Institute review of endoscopic sedation. Gastroenterology. 2007; 133(2):675-701.

2. Faigel DO, Baron TH, Goldstein JL, et al; Standards Practice Committee, American Society for Gastrointestinal Endoscopy. Guidelines for the use of deep sedation and anesthesia for GI endoscopy. Gastrointest Endosc. 2002;56(5):613-617.

3. Gross JB, Bachenberg KL, Benumof JL, et al; American Society of Anesthesiologists Task Force on Perioperative Management. Practice guidelines for the perioperative management of patients with obstructive sleep apnea: a report by the American Society of Anesthesiologists Task Force on Perioperative Management of patients with obstructive sleep apnea. Anesthesiology. 2006;104(5):1081-1093; quiz 1117-1118.

4. American Association for Study of Liver Diseases; American College of Gastroenterology; American Gastroenterological Association Institute, et al. Multisociety sedation curriculum for gastrointestinal endoscopy. Gastrointest Endosc. 2012;76(1):e1-e25.

5. Waring JP, Baron TH, Hirota WK, et al; American Society for Gastrointestinal Endoscopy, Standards of Practice Committee. Guidelines for conscious sedation and monitoring during gastrointestinal endoscopy. Gastrointest Endosc. 2003;58(3):317-322.

6. Romagnuolo J, Cotton PB, Eisen G, Vargo J, Petersen BT. Identifying and reporting risk factors for adverse events in endoscopy. Part I: cardiopulmonary events. Gastrointest Endosc. 2011;73(3): 579-585.

7. Khiani VS, Salah W, Maimone S, Cummings L, Chak A. Sedation during endoscopy for patients at risk of obstructive sleep apnea. Gastrointest Endosc. 2009;70(6):1116-1120.

8. Coté GA, Hovis CE, Hovis RM, et al. A screening instrument for sleep apnea predicts airway maneuvers in patients undergoing advanced endoscopic procedures. Clin Gastroenterol Hepatol. 2010;8(8):660-665.e1.

9. Young T, Palta M, Dempsey J, Skatrud J, Weber S, Badr S. The occurrence of sleep-disordered breathing among middle-aged adults. $\mathrm{N} \mathrm{Engl}$ J Med. 1993;328(17):1230-1235.

10. Ip MS, Lam B, Lauder IJ, et al. A community study of sleep-disordered breathing in middle-aged Chinese men in Hong Kong. Chest. 2001;119(1):62-69.

11. Jennum P, Riha RL. Epidemiology of sleep apnoea/hypopnoea syndrome and sleep-disordered breathing. Eur Respir J. 2009;33(4):907-914.

12. Chung SA, Yuan H, Chung F. A systemic review of obstructive sleep apnea and its implications for anesthesiologists. Anesth Analg. 2008;107(5):1543-1563.

13. Sleep-related breathing disorders in adults: recommendations for syndrome definition and measurement techniques in clinical research. The Report of an American Academy of Sleep Medicine Task Force. Sleep. 1999;22(5):667-689.

14. Netzer NC, Stoohs RA, Netzer CM, Clark K, Strohl KP. Using the Berlin Questionnaire to identify patients at risk for the sleep apnea syndrome. Ann Intern Med. 1999;131(7):485-491. 
15. Chung F, Ward B, Ho J, Yuan H, Kayumov L, Shapiro C. Preoperative identification of sleep apnea risk in elective surgical patients, using the Berlin questionnaire. J Clin Anesth. 2007;19(2):130-134.

16. Netzer NC, Hoegel JJ, Loube D, et al. Prevalence of symptoms and risk of sleep apnea in primary care. Chest. 2003;124(4):1406-1414.

17. Kang K, Park KS, Kim JE, et al. Usefulness of the Berlin Questionnaire to identify patients at high risk for obstructive sleep apnea: a populationbased door-to-door study. Sleep Breath. 2013;17(2):803-810.

18. Ramachandran SK, Josephs LA. A meta-analysis of clinical screening tests for obstructive sleep apnea. Anesthesiology. 2009;110(4): 928-939.
19. Chung F, Yegneswaran B, Liao P, et al. Validation of the Berlin questionnaire and American Society of Anesthesiologists checklist as screening tools for obstructive sleep apnea in surgical patients. Anesthesiology. 2008;108(5):822-830.

20. Eastwood PR, Platt PR, Shepherd K, Maddison K, Hillman DR. Collapsibility of the upper airway at different concentrations of propofol anesthesia. Anesthesiology. 2005;103(3):470-477.

\section{Publish your work in this journal}

Therapeutics and Clinical Risk Management is an international, peerreviewed journal of clinical therapeutics and risk management, focusing on concise rapid reporting of clinical studies in all therapeutic areas, outcomes, safety, and programs for the effective, safe, and sustained use of medicines. This journal is indexed on PubMed Central, CAS,
EMBase, Scopus and the Elsevier Bibliographic databases. The manuscript management system is completely online and includes a very quick and fair peer-review system, which is all easy to use. Visit http://www.dovepress.com/testimonials.php to read real quotes from published authors.

Submit your manuscript here: http://www.dovepress.com/therapeutics-and-clinical-risk-management-journal 